\title{
A cenografia na ECA-USP
}

\author{
Fausto Viana
}

T

ma boa notícia para o mundo da cenografia no país acaba de sair: está reaberto o curso de cenografia da Escola de Comunicações e Artes da Universidade de São Paulo. Depois de mais de 10 anos de inatividade, essa habilitação volta a ser oferecida, para formar cenógrafos e figurinistas que atuarão no mercado brasileiro com cenografia e indumentária. $\mathrm{O}$ momento não poderia ser mais oportuno: há uma evidente carência de profissionais formados nesta área, que tem sido dominada por profissionais oriundos da arquitetura e das artes plásticas.

Os horizontes da cenografia e indumentária se expandiram grandemente nos últimos anos. O cenógrafo não é mais aquele profissional que se dedica exclusivamente ao fazer teatral, dentro de um edifício teatral (ainda que possa fazê-lo, se assim o desejar). Há cenógrafos e figurinistas que trabalham exclusivamente em espaços teatrais alternativos, que abrigam as mais diversas produções teatrais. $\mathrm{O}$ mercado da moda abriu um novo campo de trabalho para os cenógrafos: eventos de grande porte, como a São Paulo Fashion Week, exigem elaborados trabalhos de pesquisa e realização cenográfica. A cenografia das exposições chegou com força total: fazemos aqui no Brasil, como no resto do mundo, exposições museológicas com ambientações cenográficas. Um mercado mais conhecido mas que não deve ser menos valorizado é o da cenografia das feiras e congressos. Cidades como São Paulo e Rio de Janeiro recebem este tipo de evento nas suas mais diversas variantes, de pequeno a gigantesco porte. Também não pode deixar de ser mencionado o campo das grandes festas (nas quais os cenógrafos atuam há longa data), das decorações de shoppings e lojas para datas especiais. Há designers de interiores que tratam suas ambientaçôes como se fossem cenários, que serão ocupados cotidianamente por pessoas "de verdade", "do mundo real".

A TV, que já era uma consumidora de cenários e figurinos para seus diversos programas e comerciais, vive uma nova era de expansão: as redes de TV a cabo. O mesmo acontece com a Internet, que terá agora programas com atores que serão feitos exclusivamente para serem visualizados em computadores. O cinema brasileiro volta a renascer, dando sinais de que esta nova fase de expansão deve durar mais algum tempo.

Outras "novidades" solicitam a presença de cenógrafos: os parques temáticos (vide a cenografia do Parque Hopi Hari, na cidade de Vinhedo) e os bares e restaurantes temáticos. 
O mercado de trabalho está aí - e pede bons profissionais.

Esperamos, diante desta diversidade do mercado, formar profissionais dentro do conceito da multidisciplinaridade, que é muito pertinente à essência da própria cenografia: uma fusão de muitas artes. A escultura está presente no cenário, a pintura, o desenho, as relações dramáticas e dramatúrgicas, as relações de espaço, luz, música e dança.

A tendência não é apenas nossa: este modelo já é seguido em escolas brasileiras onde há o curso de cenografia (UNIRIO e UFBA) e em outras grandes escolas internacionais de cenografia, como o da Faculdade de Artes, da Universidade do Chile (Quadro I), a Faculdade de Belas Artes da Universidade Nacional da Plata, na Argentina, a Escola Superior de Teatro e Cinema de Portugal (Quadro II), a Royal Academy of Dramatic Art de Londres (quadro III), a Tisch School of the Arts, da Universidade de Nova York (Quadro IV) e a Universidade da California, em Los Angeles, e o NIDA (National Institute of Dramatic Art), de Sydney, Austrália.Como se vê, os cursos de cenografia estão localizados nos grandes centros urbanos.

O curso da ECA-USP, moldado para ser feito em quatro anos, apresenta várias semelhanças e alguns distanciamentos em relação aos cursos supra citados. O primeiro deles é a duração: em algumas escolas norte americanas, a duração é de três anos, como em Portugal e Inglaterra. O que nos diferencia neste caso é o nível de exigência que se tem para com o aluno ingressante: nestas faculdades, pede-se que o aluno tenha um portfolio pronto, supondo-se assim que eles tenham ao menos algum nível de experiência artística em teatro ou em alguma área de expressão ligada à cenografia, como pintura, desenho ou escultura. Nestes países, estas disciplinas são levadas a bom termo no equivalente ao nosso "Ensino Médio".É uma das deficiências que teremos que suprir.

Teremos também um ciclo básico, em que o aluno de cenografia terá que necessariamente passar por aulas de expressão vocal e cor- poral, aulas de interpretação e direção, todas em nível básico, para que saiba mais sobre os assuntos que vão permear o seu fazer teatral. $\mathrm{O}$ ponto de vista do cenógrafo/figurinista será formado a partir da visão de todos os outros profissionais envolvidos na produção: o cenógrafo não será apenas um mero colaborador, mas sim um elemento participativo do processo. Este é um diferencial nosso, compartilhado com a Universidade do Chile (ver Quadro I).

\section{Quadro I}

\section{Faculdade de Artes da Universidade do Chile}

Disciplinas - $1^{\circ}$ Ano:

Semiologia

Introdução ao Vestuário

Introdução à Cenografia

Desenho Livre

Desenho Técnico

Cor e Espaço

Estruturas Dramáticas

História da Arte

História do Teatro Chileno

Curso Optativo de formação Geral

Disciplinas - 20 Ano:

Desenho e Figura Humana

Cenografia I

Iluminação I

Indumentária I

Desenho Aplicado I

Estética I

História do teatro Mundial I

Psicologia Aplicada

Maquiagem

Curso optativo de Formação Geral

Taller integrado I

Produção teatral

Disciplinas - $3^{\circ}$ Ano:

Cenografia II

Iluminação II

Indumentária II

Introdução à Interpretação

Desenho Aplicado II

História do Teatro Mundial II

Metodologia de Investigação 
Taller Integrado II

Curso Optativo de Formação Geral

Disciplinas - 40 Ano:

Direção Teatral

Cenografia III

Iluminação III

Indumentária III

Estética II

História do Teatro Latino-Americano

Seminário

Taller Integrado III

O curso da Escola Superior de Teatro e Cinema de Portugal (Quadro II) é um curso aparentemente mais curto que o nosso. Neste curso de cenografia, que tem uma das melhores e maiores cargas horárias de desenho, o aluno faz um primeiro percurso de três anos. Terminado este período, o aluno pode fazer o que eles chamam de licenciatura - equivalente à nossa especialização. Depois da especialização, ele terá necessariamente que fazer um estágio de seis meses.

\section{Quadro II}

Escola Superior de Teatro e Cinema de Portugal

Disciplinas - $1^{\circ}$ Ano:

Tecnologia de Materiais

Técnica de Desenho e Pintura

Introdução aos Figurinos

Introdução à Cenografia

Tendências das Artes Plásticas

História das Literaturas Dramáticas e do Espetáculo Teatral I

Introdução à Dramaturgia

Teorias da Arte Teatral I

Propedêutica Artística

Disciplinas - 2o Ano:

Cenotécnica

Figurinos

Cenografia

Tendências das Artes Plásticas II

História das Literaturas Dramáticas e do Espetácu-

lo Teatral II

História do Traje I

História da Decoração de Interiores I
Teorias da Arte Teatral II

Seminário

Disciplinas - 3o Ano:

Realização Plástica do Espetáculo

História do Traje II

História da Decoração de Interiores II

Seminário

Discilpinas - Licenciatura:

Teoria e Estética Teatral

Métodos e Técnicas de Investigação

Análise de Texto

Teoria e Prática da Encenação

R.P.E. - Forma e Tecnologia.

Estética e Semiótica da Cena

Artes Visuais e Artes Cênicas

Produção e Montagem do Projeto Teatral

Temos, também, muitas disciplinas comuns ao currículo de todas as universidades citadas: Desenho Cenográfico, Cenografia, História da Cenografia e Indumentária, Iluminação, Maquiagem, Fundamentos de Cenotécnica, História do Teatro e História da Arte. Outra não tão comum é Teatro e Sociedade e a naturalmente exclusiva nossa Teatro Brasileiro.

Nem tudo é tão perfeito aqui. Era de se esperar que países com grande tradição teatral, como a Inglaterra (ver Quadro III), ou de Primeiro Mundo, como EUA e Austrália oferecessem opções mais diversas. O que se percebe nos currículos destas escolas é a segmentação: enquanto aqui formamos cenógrafos $e$ figurinistas, ainda que eles possam se dedicar a apenas uma das atividades, lá eles formam cenógrafos ou figurinistas. E dentro de cada uma destas divisões maiores, eles podem ir se especializando: aderecistas, cenotécnicos, pintores de cena. Estamos falando, no entanto, de mercados culturais muito maiores que o nosso, que têm condições de empregar alguém que se especialize apenas na confecção de chapéus ou armaduras históricas. Não é o nosso caso - o nosso mercado é mais generalizante. Ainda precisamos de profissionais mais abrangentes, que possam cumprir diversas tarefas. 


\section{Quadro III}

Royal Academy of Dramatic Art de Londres

Durante um período de dois anos, os alunos terão disciplinas relacionadas às divisões do fazer cênico, como no quadro. Depois destes dois anos, o aluno recebe um certificado, mas poderá fazer mais um ano de especialização para cada uma das especialidades.

Cenografia - Inclui palestras e prática de armazenamento e manipulação dos materiais cênicos, escalas, marcações, modelagem, trabalho sobre desenhos, perspectiva, teoria das cores, desenho, pintura e texturização, orçamento e compra de materiais. Foco: formar pintores de cenário, cenógrafos e assistentes de cenógrafos.

Cenotécnica - Trabalho prático, utilização e manutenção de ferramentas, conhecimento de materiais e telas; construção, manutenção e construção de cenários em madeira e metal; mecanismos de manipulação do cenário; trabalho com plantas baixas e desenhos máquinas orçamento e compra de materiais.

Desenho de Luz - Começa com trabalhos simples de coxias, incluindo cenários, passando por todos os aspectos de luz e som, desenvolvendo luz e som para shows públicos com diretores profissionais.

Adereços - Uso dos seguintes materiais em profundidade: fibra de vidro, modelagem, máscaras me madeira. Trabalho sobre orçamentos e pesquisa para se encontrar os melhores materiais

Guarda Roupa - Palestras e práticas sobre as habilidades básicas para se trabalhar com guarda roupas, desde a sua manutenção à alteração, tingimento, chapelaria, manutenção básica de perucas, corte de moldes, interpretação histórica de figurinos, pesquisa e compra.

\section{Quadro IV}

Tisch School of the Arts, da Univ. de Nova York

Opção: Cenografia

Primeiro Ano:

Desenho Cênico I

Cenotécnica I

História do Traje e do Cenário

Fundamentos de Desenho

Esboços e Construção de Modelos

Segundo Ano:

Desenho Cênico II

Estúdio de Cenários

Desenho Avançado

Desenho Computadorizado para Teatro e Cinema

Fundamentos Conceituais de design

Produção do Segundo Ano

Terceiro Ano:

Desenho Cênico III

Pintura de Cena

Introdução ao Design de Luz

Tese/Portfolio

Produção do Terceiro Ano

Opção: Indumentária

Primeiro Ano:

Desenho de Figurinos I

Desenho da Figura Humana

Cenotécnica I

Corte e Moldes (costura)

História do Traje e do Cenário

Segundo Ano:

Desenho de Figurinos II

Estúdio de Figurinos

Desenho da Figura Humana II

Fundamentos Conceituais de Design

Produção do Segundo Ano

Terceiro Ano:

Desenho de Figurinos III

Introdução ao Design de Luz

Conexôes (Literatura Dramática)

Tese/Portfolio

Produção do Terceiro Ano 


\section{0 nosso currículo experimental}

A seguir apresentamos o currículo aprovado para a reabertura do curso, que já está em teste. A partir dele e dos resultados obtidos, efetuaremos as mudanças que se fizerem necessárias.

$1^{\circ}$ Período Ideal

Disciplinas Obrigatórias:

CAC0232 - Improvisação I

CAC0236 - História do Teatro I

CAC0242 - Jogos Teatrais I

CAC0262 - Expressão Vocal I

CAC0266 - Expressão Corporal I

CAC0313 - Teatro e Sociedade I

CAC0360 - Coro Cênico I

Disciplinas Optativas:

CCA0272 - Estética e História da Arte I

CCA0279 - Fundamentos da Expressão e Comunicação Humanas

2o Período Ideal

Disciplinas Obrigatórias:

CAC0233 - Improvisação II

CAC0237 - História do Teatro II

CAC0243 - Jogos Teatrais II

CAC0263 - Expressão Vocal II

CAC0267 - Expressão Corporal II

CAC0314 - Teatro e Sociedade II

CAC0362 - Coro Cênico II

Disciplinas Optativas:

CCA0273 - Estética e História da Arte II

CAC0200 - Folclore Brasileiro

3o Período Ideal

Disciplinas Obrigatórias:

CAC0203 - História da Cenografia e Indumentária I

CAC0238 - História do Teatro III

CAC0268 - Expressão Corporal III

CAC0269 - Expressão Vocal III

CAC0370 - Teatro Brasileiro I

CAC0371 - Interpretação I

CAC0391 - Cenografia I

Disciplinas Optativas:

CAC0352 - Ação Cultural em Teatro

CAC0363 - Coro Cênico III

CAC0253 - Mímica I

4o Período Ideal

Disciplinas Obrigatórias:

CAC0205 - História da Cenografia e Indumentária II
CAC0239 - História do Teatro IV

CAC0372 - Teatro Brasileiro II

CAC0373 - Interpretação II

CAC0374 - Direção Teatral I

CAC0392 - Cenografia II

Disciplinas Optativas:

CAC0364 - Coro Cênico IV

CAC0273 - Expressão Corporal IV

CAC0274 - Expressão Vocal IV

CAC0375 - Iluminação I

CAC0254 - Mímica II

50 Período Ideal

Disciplinas Obrigatórias:

CAC0259 - Teoria do Teatro I

CAC0377 - Iluminação II

CAC0393 - Cenografia III

CAC0395 - Desenho e Materiais Cenográficos I

CAC0398 - Indumentária

Disciplinas Optativas:

CAC0298 - Dramaturgia I

CAC0350 - Expressão Corporal V

CAC0278 - Expressão Vocal V

CAC0381 - Mímica III

CAC0282 - Música e Ritmo

CAC0247 - Teatro de Animação I

CAC0385 - Técnica de Dança I

6o Período Ideal

Disciplinas Obrigatórias:

CAC0260 - Teoria do Teatro II

CAC0394 - Cenografia IV

CAC0396 - Desenho e Materiais Cenográficos II

CAC0397 - Cenotécnica

Disciplinas Optativas:

CAC0270 - Canto para o Ator

CAC0261 - Dramaturgia II

CAC0351 - Expressão Corporal VI

CAC0279 - Expressão Vocal VI

CAC0296 - Maquiagem e Caracterização

CAC0382 - Mímica IV

CAC0277 - Sonoplastia

CAC0248 - Teatro de Animação II

CAC0386 - Técnica de Dança II

70 Período Ideal

Disciplina Obrigatória:

CAC0307 - Projeto de Cenografia Teatral I

$8^{\circ}$ Período Ideal

Disciplina Obrigatória:

CAC0308 - Projeto de Cenografia Teatral II 
Através de pequenos ajustes no currículo, teremos a possibilidade de enviar nossos alunos, nos moldes do que vem acontecendo hoje, aos diferentes departamentos da Universidade. Desenho de Observação, Desenho da Figura Humana, Luz e Sombra em Artes Plásticas e Instalação são disciplinas a serem cursadas no Departamento de Artes Plásticas da ECA. A disciplina Maquetes deverá ser cursada na Faculdade de Arquitetura e Urbanismo da USP. Esta busca por disciplinas de outros departamentos é benéfica, como comprova a experiência das universidades estrangeiras que mencionamos, por vários motivos. $\mathrm{O}$ principal deles, no caso do Campus da USP, é superar as distâncias entre as unidades, que segundo alguns estudiosos são uma herança dos tempos militares que não desejavam ver a união entre estudantes. Esta relação entre os alunos de diversos cursos é extremamente benéfica, principalmente em função das possíveis relações profissionais no futuro mercado de trabalho. A troca de conhecimentos pode atingir níveis muito elevados, beneficiando os estudantes de todas as unidades, que virão também até nós, como tem acontecido, em busca de cursos de cenografia que os ajudem em seus projetos. Não se justifica mais o isolamento entre as unidades e a luta individualizada para manter seus cursos "embaixo dos olhos". O que se deseja é a troca de informações, não a manipulação delas.

Quem poderia dar um curso especializado de Desenho de Observação melhor do que um profissional qualificado? Da mesma forma, quem ensinaria melhor a Cenografia do que alguém treinado para isso? Este é um dos aspectos mais interessantes que a Universidade de São Paulo tem a oferecer - seus profissionais. Professores que são também profissionais atuantes tanto no mercado como na pesquisa.

Queremos também integrar nossos alunos dos diferentes cursos do próprio Departamento de Artes Cênicas, estabelecendo também já na Universidade futuros canais empregatícios e colaborativos. Os alunos de direção, cenografia, interpretação e teoria estudarão juntos, de- senvolvendo possibilidades, pesquisando novos e antigos caminhos. Os alunos de cenografia trabalharão também junto aos outros alunos em seus projetos práticos de direção e interpretação. Esta integração dos alunos de uma mesma unidade também não é uma característica comum a todos os cursos de faculdades estrangeiras.

Em médio prazo, desejamos que os alunos dos diferentes anos de cenografia possam se integrar a um mesmo ambiente, no mesmo horário, em determinadas oportunidades. Serão aulas coletivas. Cada um desenvolverá seus projetos de acordo com os conhecimentos previamente adquiridos e recebendo de um orientador e de convidados novas informaçôes adequadas ao seu crescimento educacional. No entanto, esse interrelacionamento dos futuros colegas profissionais aprofundará a troca entre os atuais aprendizes.

Um conceito um pouco Renascentista? Talvez. No entanto, temos que ter em mente que a Cenografia não é apenas uma profissão: é um ofício. Quem aprende ensina para o outro, que transmite seus conhecimentos para outrem, e assim está garantida a perpetuidade desta arte. Mesmo depois de formados, esses alunos poderão voltar e dividir seus conhecimentos com os demais. Estimularemos também assim a pesquisa em cenografia e indumentária em nível de pós-graduação.

O entusiasmo pelo que conseguimos até agora, no entanto, não deve fazer com que se ignore o trabalho que ainda está por vir. Dentre os principais problemas, temos a inadequação do espaço físico para expansão das atividades. Falta equipamento de boa qualidade para a exibição de vídeos e imagens, bem como recursos orçamentários para disciplinas que necessitem de experimentaçōes práticas, como Cenotécnica. Superar também os entraves burocráticos da estrutura acadêmica também será um grande passo. Trabalhamos neste momento, por exemplo, tentando superar bloqueios nos computadores que impedem o acesso de alunos de outras unidades à nossa, e vice-versa. A grande mudança, que aguardamos ansiosamente, será a nova estrutura do vestibular, garantindo que os can- 
didatos interessados em Cenografia não tenham que ser avaliados por um exame que inclui provas de interpretação e nenhuma avaliação de cenografia ou desenho. Que ao menos trabalhos anteriores, os portfolios, sejam examinados.

Seguiremos adiante. Na cidade de São Paulo não há nenhuma outra instituição universitária que ofereça esta habilitação em cenografia, uma arte tão antiga quanto o próprio teatro. Existe a opção por cursos de cenografia rápidos, que permitem que os alunos possam ter contato com o fazer cenográfico. Esperamos também que esta retomada da Escola de Comunicações e Artes sirva de estímulo para que outras instituições, de nível técnico, possam estimular o surgimento de novos profissionais parceiros dos cenógrafos e figurinistas: os cenotécnicos, maquinistas e as costureiras especializadas em teatro.

A aventura está apenas começando. 